\title{
Segmental Fracture of Both Bones with Ipsilateral Condyle of Tibia Fracture - A Case Report
}

\author{
Nithin $\mathrm{S}^{1 *}$ and Sreehari C $\mathrm{K}^{2}$ \\ ${ }^{1}$ Department of Orthopedics, AKG Memorial Cooperative Hospital, India \\ ${ }^{2}$ Department of Orthopedics, Pariyaram Medical College, India
}

Submission: September 29, 2016; Published: October 17, 2016

*Corresponding author: Nithin S, Consultant Orthopaedic surgeon, Department of Orthopedics, AKG Memorial Cooperative Hospital, Kannur, Kerala, India,

\begin{abstract}
Segmental fracture both bone associated with lateral condyle fracture on the same side is very rare. Segmental tibia fracture is defined by the presence of two distinct fracture lines separating the cortical and completely isolating an intermediary segment of the tibia. Segmental tibia fractures are uncommon injuries that occur in about $12.8 \%$ of tibial fractures. Most are caused by high-energy trauma. It is estimated that almost more than half of these fractures are open fractures. They are often part of multiple injuries. It often is a challenge to manage such cases as they have a significant complication rate.

As such there are very few article on the management of segmental tibia fractures. There has been a significant change in the management of these injuries. This has been made possible by the development of new orthopedic implants. Few of them are intramedullary locking nail, external Fixators and Plaster of Paris. It is important to note that more than two-thirds of segmental tibia fractures will require more than one surgical intervention. The surgeon therefore, needs to plan ahead to make subsequent surgical interventions possible.
\end{abstract}

\section{Introduction}

A segmental fracture is defined as a fracture with two or more fracture lines with one or more cylindrical intercalary segment(s). The majority of segmental tibia fractures have one intercalary segment. These fractures are rarely encountered, accounting for only up about $12.8 \%$ of tibial fractures [1]. They are caused by high-energy injuries; motor vehicle and motorcycle crashes, falls from a height industrial and train accidents. Some are caused by low - energy injuries such as sports and twisting the leg. The incidence of open segmental fractures varies considerably from study to study; it ranges from $37.5 \%$ to $83.8 \%[2,3]$. Segmental tibial fractures are often part of multiple injuries. Segmental fracture of both bones is quite a rarity. Along with that we have lateral tibial condyle fracture. Hence it was one of the challenging case for the treating Orthopaedic Surgeon.

\section{Case Report}

A 38 year old male presented to the casualty with history of RTA. He came to our institute with complaints of swelling of the right lower limb. There were no external wounds, but there were extensive grazed abrasions on the anterior aspect of right leg. His vitals were normal. No head injury or any other solid organ injury. Plain X-ray showed a Segmental fracture of both bone along with lateral condyle fracture of tibia (Figure 1). He was assessed for other co morbid conditions [4]. He was fit for the surgical procedure. He was taken up for surgery. Treated by closed reduction and internal fixation by using interlocking tibial nail. Fibula was fixed with a rush pin. Lateral condyle fracture of tibia was fixed with cannulated cancellous screw along with a washer. Post operative recovery was uneventful. Immediate post op x-ray showed a satisfactory reduction of fracture (Figure 2). Later he was put on non weight bearing of right leg for 6 weeks. Later $\mathrm{x}$-ray was taken at 1 year post operative (Figure3).

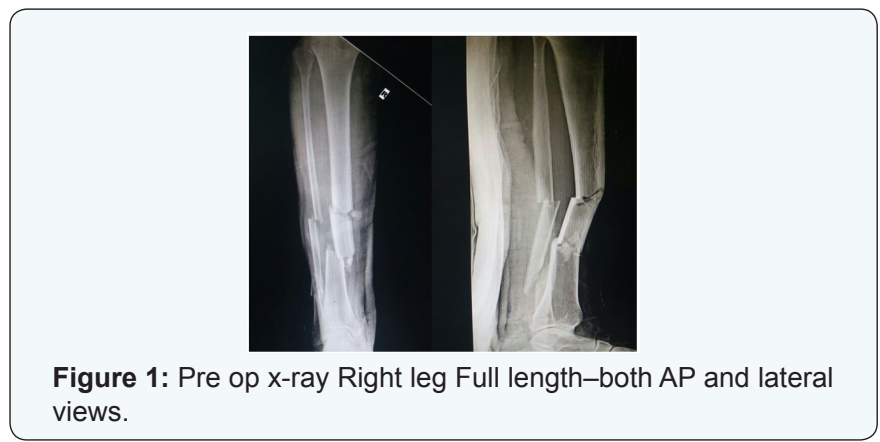




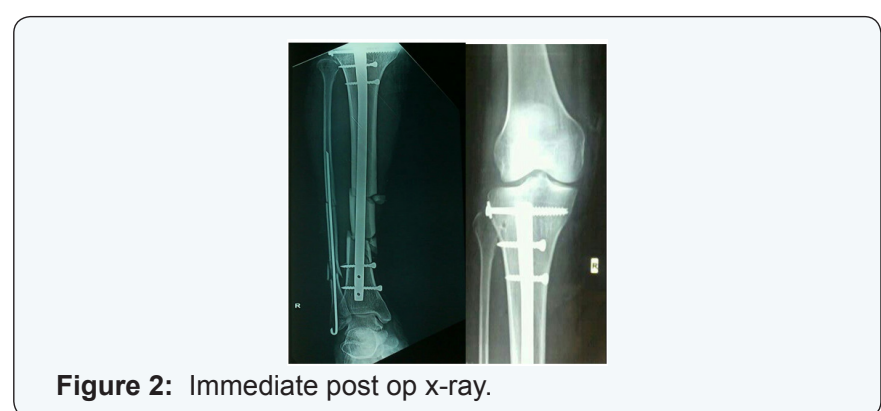

Figure 2: Immediate post op x-ray

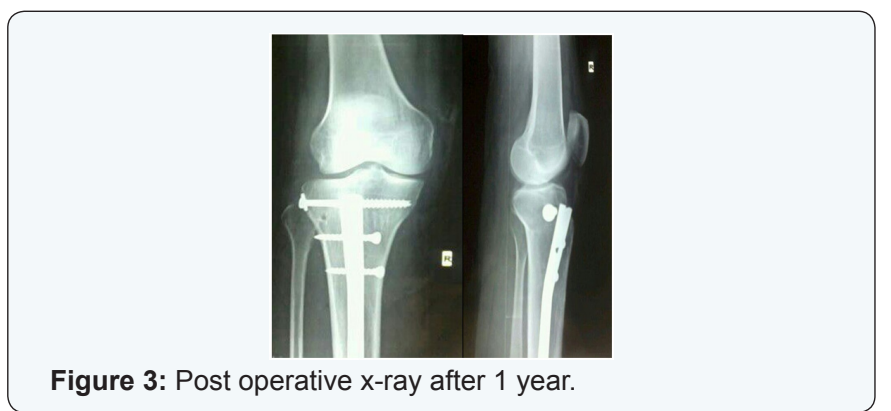

Discussion

Boylston et al. [5] forty years ago reviewed 28 patients and outlined treatment options for segmental tibial fractures. The options werefew technique and implants like:
a) Cast immobilization
b) Plating
c) Rods
d) Single screw
e) Rod and plate
f) Fibular rod

They followed their patients for an average of 26 months (12 -51 months). There were 2 non-unions; one patient was treated with cast and the other with a plate. There were 13 patients with open fractures. It is not clear how patients were allocated. However, the methods laid the foundation for the management of segmental tibial fractures. The implants have improved over the years but the principles of treatment have not changed dramatically over these years. In 1969, Zucman and Maurer [6] introduced the technique of unreamed tibial nailing in the management of both closed and open segmental fractures. There was no grading of open fractures as we know it today. They found that $19 / 36$ (79\%) of open fractures achieved union without complications. There were two cases of non-union of closed fractures. Deep sepsis developed in four cases (12\%); two of these united without any surgical intervention. Tibial nailing was to be the major technique in the management of these fractures as will be evident in subsequent cases.

Functional outcome of segmental tibial fractures was not documented in the majority of previous reports. Oivind \& Olav [7] reviewed 54 patients with the aim of documenting functional outcome. They found that $53.7 \%$ of their patients had full recovery and the rest had some form of functional impairment. Their assessment was to have great impact to subsequent authors: it was clear that closed segmental fractures should be viewed differently from open ones. It was Melis et al. [8] who, in their reviews of 38 patients separated the treatment of open and closed segmental tibial fractures. They used reamed K-nailHertzog nail. Open fractures were treated with antibiotics for 20 days plus continuous irrigation and suctioning for at least 10 days. Soft tissue coverage was done after 10 days. They clearly documented all complications which occurred that included skin breakdown, melanin and sepsis.

They noted that skin breakdown did occur in closed fractures as well. Woll \& Duwelius [4] used Ender nails in both closed and open fractures. All fractures united. The few complications they encountered included superficial sepsis, DIC, shortening and melanin. Complications associated with this kind fracture were mal-union and shortening. But in our patient it was not the case. At follow up patient recovered well with no residual co morbidity. Giannoudis et al. [1] findings send a very important message that " $66.6 \%$ of segmental tibial fractures require more than one surgical intervention". It is therefore extremely vital to plan ahead so that should subsequent surgical interventions become necessary, the surgeon is well prepared for it. This

planning ahead implies re-aligning the medullary cavity from the start.

\section{Conclusion}

As per the literature no cases has been reported with segmental fracture of both bones with lateral condyle fracture. And currently there is no comprehensive classification of this type of fracture. An ideal classification needs to take into account the extend of soft tissue damage and offer a guideline in the management. We need a large series of cases to be able to assess the functional outcome of segmental both bone fracture. We must use a validated outcome measure or scale. There is a need to do multi-centre collaboration because these fractures are rare. Future clinical studies need to address all outstanding issues discussed above. There are no clear therapeutically relevant guidelines regarding classification of segmental both bonefractures, treatment approaches and evaluation of functional outcome using validated scales. These are the crucial issues or challenges facing future clinical research studies.

\section{References}

1. Giannoudis PV, Hinsche AF, Cohen A, Macdonald DA, Matthews SJ, et al. (2003) Segmental tibial fractures: an assessment of procedures in 27 cases. Injury 34(10): 756-762.

2. Merianos P, Papagiannakos K, Scretas E, Smyrnis P (1988) Ender nails for segmental tibial fracture. Early weight bearing in 22 cases. Acta Orthop Scand 59(3): 297-301.

3. Woll TS, Duwelius PJ (1992) The segmental tibial fracture Clin Orthop Relat Res (281): 204-207.

4. Chiu-Chuan Wu and Chun- Hsiung Shih (1993) Segmental tibial fractures treated with Interlocking Nailing. Journal of Orthopaedic Trauma 7(5): 468-472. 
5. Boylston BF, Milam R (1957) Segmental fractures $f$ the Tibia: an analysis of thirty cases. South Med J 50(8): 969-975.

6. Zucman J, Maurer P (1969) Two-level fractures of the tibia. Results in thirty six cases treated by blind nailing. J Bone Joint Surg Br 51(4) 686-693.
7. Langård O, Bo O (1976) Segmental tibial shaft fractures. Acta Orthop Scand 47(3): 351-357.

8. Melis GC, Sotgiu F, Lepori M, Guido P (1981) Intramedullary nailing in Segmental Tibial Fractures. J Bone Joint Surg Am 63(8): 1310-1318. 